\title{
FÉCULA DE MANDIOCA E FARINHA DE AVEIA COMO SUBSTITUTOS DE GORDURA NA FORMULAÇÃO DE HAMBÚRGUER DE CARNE OVINA ${ }^{1}$
}

\author{
Larissa Mont'Alverne Jucá SEABRA², Jorge Fernando Fuentes ZAPATA ${ }^{2, *}$, \\ Cynthia Monteiro NOGUEIRA², Maria Alcilene DANTAS ${ }^{2}$ e Roselúcia Barrôzo de ALMEIDA²
}

\begin{abstract}
RESUMO
Nos produtos cárneos com teor de gordura reduzido, ingredientes têm sido utilizados para manter os atributos de qualidade e rendimento. As farinhas de mandioca e de aveia têm sido usadas como componentes úteis para melhorar as características de suculência e maciez em hambúrgueres com baixo nível de gordura. O objetivo do presente estudo foi verificar o efeito da fécula de mandioca e da farinha de aveia sobre as características físicas, químicas e sensoriais de hambúrgueres de carne ovina com teor de gordura reduzido. Foram testadas 4 formulações à base de carne ovina limpa: testemunha sem gordura adicionada (F1), com 9,15\% de gordura ovina adicionada (F2), sem gordura adicionada e $2 \%$ de fécula de mandioca (F3) e sem gordura adicionada e $2 \%$ de farinha de aveia (F4). Foram avaliados durante o cozimento: composição centesimal, rendimento, encolhimento e capacidade de retenção de água, força de cisalhamento, cor e análise sensorial dos hambúrgueres. Os produtos nos quais foram adicionados os substitutos de gordura (F3 e F4) apresentaram menor teor de gordura, antes e depois de cozidos, menor encolhimento, maior rendimento e capacidade de retenção de água do que os das formulações F1 e F2. A força de cisalhamento e a intensidade de vermelho ( $\mathrm{a}^{*}$ ) foram menores nos produtos aos quais foram adicionados os substitutos de gordura (F3 e F4) do que nos produtos sem substituição (F1 e F2). Não foram detectadas diferenças na aceitação global dos produtos com diferentes formulações. Desta forma, conclui-se que o uso de fécula de mandioca e farinha de aveia pode ser uma alternativa de substituição de gordura em produtos de carne ovina de baixo nível de gordura tipo hambúrguer.
\end{abstract}

Palavras-chave: substitutos de gordura; capacidade de retenção de água; força de cisalhamento; cor da carne.

\section{SUMMARY}

CASSAVA STARCH AND OATMEAL AS FAT REPLACERS OF LAMB BURGERS. Several ingredients have been successfully tested as fat replacers in meat products maintaining desirable attributes like tenderness, juiciness and cooking yield. Cassava starch and oatmeal have been used to maintain good texture, juiciness and overall acceptance in low-fat burgers. The objective of this study was to verify the effect of cassava starch and oatmeal on physical, chemical and sensory characteristics of low-fat lamb burgers. Four formulations containing lean lamb meat were tested: lean meat without added fat (F1); lean meat plus $9,15 \%$ added fat (F2); lean meat plus $2 \%$ cassava starch (F3) and lean meat plus $2 \%$ oatmeal (F4). The products were tested for chemical composition, cooking yield, shrinkage and water holding capacity, shear force, color and sensory analysis. The products with fat replacers (F3 and F4) had lower fat levels in both raw and cooked products, lower shrinkage and higher yield and water holding capacity after cooking than products without fat replacers (F1 and F2). Shear force and redness ( $\mathrm{a}^{*}$ value) were lower in products with fat replacers (F3 and F4) as compared to those without these ingredients (F1 and F2). No differences were detected on overall acceptability of burgers from the different formulations. Thus, the use of cassava starch or oatmeal can be a good alternative for fat replacement in low-fat lamb burgers.

Keywords: fat replacers; water holding capacity; shear force; meat color.

\section{1 - INTRODUÇÃO}

Nos últimos anos especial atenção tem sido dada aos perigos das dietas ricas em gorduras, e como conseqüência, observa-se uma crescente valorização dos produtos com quantidades reduzidas desse componente. Atualmente se observa uma intensa competição entre os setores de desenvolvimento de produtos nas indústrias, para oferecer aos consumidores alimentos com baixo teor de gordura. Os produtos cárneos convencionais possuem um alto nivel de gordura (20 a 30\%), permitindo desta forma, uma grande oportunidade para sua redução. A maioria dos hambúrgueres com teor de gordura reduzido possui cerca de $10 \%$ desse componente [12].

A diminuição do teor de gordura em produtos cárneos, no entanto, geralmente implica na redução de atributos de qualidade como maciez, suculência e rendi-

\footnotetext{
Recebido para publicação em 18/02/2000. Aceito para publicação em 23/03/2002.

2. Universidade Federal do Ceará-Departamento de Tecnologia de Alimentos, Telefone: (85) 2889743, Cx. Postal 12168, CEP 60020-181, Fortaleza-CE.E-mail: zapata@ufc.br.

* A quem a correspondência deve ser enviada.
}

mento [20]. Os substitutos de gordura têm sido classificados pela AMERICAN DIETETIC ASSOCIATION [2], de acordo com sua composição, em substâncias com base nos carboidratos, proteínas, lipídios ou combinações destes. Pesquisas têm verificado que aqueles provenientes dos carboidratos como gomas, amidos e fibras, entre outros, melhoram as propriedades sensoriais de hambúrgueres com teor de gordura reduzido, quando usados em concentrações de até $3 \%[3,8,10,20,21]$. O uso de fécula de mandioca, um produto amplamente disponivel no mercado local, em produtos cárneos se apresenta promissor considerando que o amido deste tubérculo começa a gelatinizar na mesma temperatura em que a carne começa a cozer. Isto significa que será necessária uma menor quantidade de amido de mandioca que de amidos de outro tipo para reter água e obter produtos suculentos [16].

As vantagens de se usar farinhas de aveia em produtos cárneos têm sido justificadas pela sua habilidade de reter água nesses alimentos, inclusive durante o cozimento, por dar a sensação bucal similar à da gordura, pela ausência de sabor de cereais e porque contribui com fibra dietética nos produtos cárneos [7, 9, 17]. 
A carne com reduzido nivel de gordura pode encontrar limitada aceitação pelo consumidor. Segundo MILLER et al. [15], a obtenção de hambúrgueres com baixos níveis de gordura (aproximadamente 10\%) que apresentem a aceitação e preferência dos hambúrgueres tradicionais (aproximadamente 22\% de gordura) continua sendo um desafio para a indústria da carne.

A carne obtida da desossa e limpeza manual da perna de ovinos tropicais provenientes do cruzamento das raças Santa Inês ou Somalis Brasileira com Crioula apresenta valores de gordura variando de 2,01\% a 2,39\%, dependendo do regime de acabamento dos animais [24]. Esses baixos niveis de lipídios podem levar a uma limitada preferência sensorial dos hambúrgueres preparados com este tipo de carne. Por outro lado, o conteúdo de ácidos graxos saturados na carne ovina que se apresenta similar ou superior ao da carne bovina [5] é também uma preocupação do consumidor atual.

O desenvolvimento de produtos formulados, de valor agregado, com carnes menos tradicionais como a caprina e ovina, poderia atrair o crescente mercado de produtos com teor reduzido de gordura e com boas caracteristicas sensoriais [9]. Desta forma, o presente experimento teve como objetivo verificar o efeito do uso da fécula de mandioca e da farinha de aveia como substitutos parciais da gordura ovina, sobre as caracteristicas de qualidade de hambúrgueres formulados com este tipo de carne.

\section{2 - MATERIAL E MÉTODOS}

\section{1 - Formulação dos hambúrgueres}

Para a formulação dos hambúrgueres foi utilizada a carne da perna proveniente de animais ovinos SRD, machos inteiros, com aproximadamente 12 meses de idade. Após a desossa, a carne foi limpa retirando-se a gordura e o tecido conectivo aparente. A carne limpa e a gordura foram então picadas, separadamente, em moinho equipado com lâmina de $10 \mathrm{~mm}$ de diâmetro a uma temperatura de $5-10^{\circ} \mathrm{C}$. A carne limpa foi utilizada para a formulação F1. A formulação F2 utilizou, além da carne limpa, 9,15\% da gordura ovina picada. Nas formulações F3 e F4 foram utilizados $2 \%$ de fécula de mandioca (polvilho doce HIKARI, Ferraz de Vasconcelos, SP) e 2\% de farinha de aveia (farinha de aveia integral MÃE TER$\mathrm{RA}$, São Paulo, SP), respectivamente, de acordo com a Tabela 1. A massa de carne obtida foi misturada por 6 minutos e em seguida foram adicionadas a fécula de mandioca ou a farinha de aveia dissolvidas na água e o sal. A massa de todas as formulações foi então picada com lâmina de $5 \mathrm{~mm}$ de diâmetro. Os hambúrgueres, pesando $113 \mathrm{~g}$, foram formatados manualmente com o auxilio de placas de Petri descartáveis e congelados em caixas de papelão parafinado. Depois de congelados, foram embalados a vácuo e mantidos em congelamento a $-20^{\circ} \mathrm{C}$ até o momento das análises.
TABELA 1. Percentuais dos ingredientes usados nas formulações de hambúrgueres de carne ovina.

\begin{tabular}{|c|c|c|c|c|}
\hline \multirow[b]{2}{*}{ Ingredientes (\%) } & \multicolumn{4}{|c|}{ Formulações } \\
\hline & F1 & $\mathrm{F} 2$ & $\mathrm{~F} 3$ & $\mathrm{~F} 4$ \\
\hline Carne limpa & 91,50 & 82,35 & 89,50 & 89,50 \\
\hline Gordura adicionada & - & 9,15 & - & - \\
\hline Água & 8,00 & 8,00 & 8,00 & 8,00 \\
\hline Sal & 0,50 & 0,50 & 0,50 & 0,50 \\
\hline Fécula de mandioca & - & - & 2,00 & - \\
\hline Farinha de aveia & - & - & - & 2,00 \\
\hline
\end{tabular}

\section{2 - Composição centesimal}

As determinações de umidade, cinzas, proteína e gordura foram realizadas em triplicata, tanto nos hambúrgueres crus como nos cozidos, segundo A.O.A.C. [4].

\section{3 - Rendimento na cocção}

Após descongelamento a $4^{\circ} \mathrm{C}$ por 12 horas, os hambúrgueres foram cozidos, em chapa aquecida por gás, por aproximadamente 12 minutos, sendo virados a cada 2 minutos até alcançarem uma temperatura interna de $71^{\circ} \mathrm{C}$, monitorada através de termômetro digital equipado com termopar de cobre/"constantan" (Delta OMH, modelo HD9218, Itália). O percentual de rendimento na cocção foi calculado pela diferença entre o peso da amostra crua e da cozida, de acordo com BERRY [7]:

$\%$ rendimento $=\frac{\text { Peso da amostra cozida }}{\text { Peso da amostra crua }} \times 100$

\section{4 - Porcentagem de encolhimento}

A porcentagem de encolhimento foi determinada segundo BERRY [7], através da seguinte relação:

\% encolhimento $=($ Diâm. da am. crua - Diâm. da am. cozida $) \times 100$

Diâmetro da amostra crua

\section{5 - Capacidade de retenção de água}

A capacidade de retenção de água (CRA) foi calculada de acordo com TROY, DESMOND, BUCKEY [20], através da seguinte equação:

$\% \mathrm{CRA}=1-\underline{\mathrm{A}-\mathrm{D}} \times 100$

$\mathrm{U}$

Onde:

$A=$ peso da amostra (g) antes do aquecimento

$\mathrm{D}=$ peso da amostra $(\mathrm{g})$ após aquecimento e centrifugação

$\mathrm{U}=$ total de água na amostra (\%) (baseada na umidade do hambúrguer) 


\section{6 - Força de cisalhamento}

Foram utilizados hambúrgueres cozidos da forma descrita acima. De cada amostra foram retirados, em dois lugares diferentes, dois pedaços de $2,5 \mathrm{~cm}$ de comprimento. Determinou-se a força de cisalhamento de acordo com ABULARACH, ROCHA, FELICIO [1], em texturômetro TA-XT2 (Stable Micro System, Surrey, England), equipado com célula de Warner-Bratzler, operando com velocidade de $20 \mathrm{~cm} / \mathrm{s}$.

\section{7 - Medição de cor}

A medição de cor das amostras cozidas foi realizada em colorimetro Minolta CR 300 (Osaka, Japão), operando no sistema CIE, para medir os parâmetros $\mathrm{L}^{*}, \mathrm{a}^{*} \mathrm{e} \mathrm{b}^{*}$, de acordo com JAMES \& BERRY [13].

\section{8 - Análise sensorial}

O teste de aceitação global foi realizado utilizandose escala hedônica de 9 pontos ( 9 = gostei muitíssimo; 1 = desgostei muitíssimo), segundo STONE \& SIDEL [18] e a atitude de compra, utilizando-se escala de 5 pontos ( 5 = eu certamente compraria o produto; $1=$ eu certamente não compraria o produto). O teste contou com um painel de 40 consumidores não treinados, que receberam as amostras dos tratamentos, uma de cada vez.

\section{9 - Análise estatística}

Para verificar o efeito das formulações sobre os parâmetros estudados, foi realizada a análise de variância dos dados e para a comparação de médias o teste de Tukey $(\mathrm{p}<0,05)$.

\section{3 - RESULTADOS E DISCUSSÃO}

De acordo com o esperado, verificou-se que os hambúrgueres sem adição de gordura ou substitutos (F1) apresentaram menor $(\mathrm{p}<0,05)$ nivel deste componente que os adicionados de gordura $(F 2)$ e maior $(p<0,05)$ nivel que os adicionados de amido (F3 e F4), provavelmente devido ao efeito diluente desses ingredientes nas formulações (Tabela 2). No cozimento dos hambúrgueres as perdas de umidade e gordura foram maiores $(p<0,05)$ no produto contendo farinha de aveia que naquele contendo fécula de mandioca. Resultados similares foram obtidos por DESMOND, TROY, BUCKLEY [10] os quais registraram que o aumento do nivel de amido de mandioca em hambúrgueres de carne bovina melhorava a suculência e maciez do produto quando comparado aos efeitos dos ingredientes fibra de aveia e proteínas do soro, usados com o mesmo propósito.

Os niveis de gordura nos hambúrgueres contendo fécula de mandioca e farinha de aveia $(2,03$ e 2,36\%, respectivamente, nos produtos crus e 4,94 e $2,94 \%$, respectivamente, nos produtos cozidos), foram inferiores aos reportados por TROY, DESMOND, BUCKEY [20], que estudando o efeito da adição de $1,5 \%$ de amido de mandioca e $1,0 \%$ de fibra de aveia em hambúrgueres de carne bovina encontraram $9,10 \%$ e $11,90 \%$ de gordura nos produtos crus e cozidos, respectivamente. De acordo com o Handbook 8-13 do USDA [22], que é a fonte usada para verificar a composição dos produtos cárneos nos Estados Unidos, os hambúrgueres classificados como "regular" possuem teor de gordura de $17,06 \%$ a 26,55\%.

A Portaria 234 de 21/05/1996 do Ministério da Saúde [6] define como "reduzido em gordura", o produto que apresenta uma redução mínima de $25 \%$ de gordura quando comparado ao produto convencional e "baixo em gordura", quando o teor de gordura for menor que 3\%, nos produtos sólidos. No presente trabalho, poder-se-ia classificar os hambúrgueres formulados com fécula de mandioca (F3) como tendo teor reduzido de gordura, já que apresentaram redução de 75,30\% (4,94\% de gordura) em relação aos produtos convencionais formulados com carne bovina, que possuem cerca de $20 \%$ de gordura antes do cozimento [11, 23]. Já os hambúrgueres adicionados de farinha de aveia (F4) apresentaram 2,94\% de gordura, podendo ser considerados como alimento de "baixo teor de gordura" de acordo com a legislação vigente.

Os valores de proteina variaram de 17,02 a $18,88 \%$ nos hambúrgueres crus e de 23,82 a $28,47 \%$ nos cozidos (Tabela 2). Nos produtos cozidos, como era de se esperar, a formulação sem gordura ou substitutos adicionados $(F 1)$ apresentou o maior $(p<0,05)$ conteúdo de proteína. Já a formulação que utilizou fécula de mandioca (F3) apresentou o menor teor de proteína no produto cozido. Isto pode ter sido devido ao alto nivel de umidade residual $(68,99 \%)$ neste produto e, provavelmente, ao fato da fécula de mandioca conter menos proteína que a farinha de aveia. Similarmente, TROY, DESMOND, BUCKEY [20], encontraram 27,4\% de proteína em hambúrgueres de carne bovina adicionados com uma mistura de fécula de mandioca e fibra de aveia.

TABELA 2. Composição média ${ }^{1}(n=2)$ de hambúrgueres de carne ovina antes e depois do cozimento.

\begin{tabular}{cccccc}
\hline \multirow{4}{*}{ Cru } & Formulação & Umidade (\%) & Gordura (\%) & Proteína (\%) & Cinzas (\%) \\
& F1 & $76,34^{\mathrm{a}}$ & $4,16^{\mathrm{d}}$ & $18,88^{\mathrm{e}}$ & $1,16^{\mathrm{cd}}$ \\
& F2 & $70,43^{\mathrm{b}}$ & $12,08^{\mathrm{b}}$ & $17,02^{\mathrm{f}}$ & $1,04^{\mathrm{d}}$ \\
& F3 & $76,38^{\mathrm{a}}$ & $2,03^{\mathrm{e}}$ & $17,98^{\mathrm{ef}}$ & $1,06^{\mathrm{d}}$ \\
& Fozido & $76,00^{\mathrm{a}}$ & $2,36^{\mathrm{e}}$ & $18,56^{\mathrm{e}}$ & $1,10^{\mathrm{d}}$ \\
& F1 & $63,60^{\mathrm{e}}$ & $7,74^{\mathrm{c}}$ & $28,47^{\mathrm{a}}$ & $1,59^{\mathrm{a}}$ \\
& F2 & $57,88^{\mathrm{f}}$ & $16,15^{\mathrm{a}}$ & $26,65^{\mathrm{b}}$ & $1,48^{\mathrm{ab}}$ \\
& F3 & $68,99^{\mathrm{c}}$ & $4,94^{\mathrm{d}}$ & $23,82^{\mathrm{d}}$ & $1,26^{\mathrm{c}}$ \\
& F4 & $67,99^{\mathrm{d}}$ & $2,94^{\mathrm{e}}$ & $24,85^{\mathrm{c}}$ & $1,44^{\mathrm{b}}$
\end{tabular}

${ }^{1}$ Médias acompanhadas pela mesma letra, na mesma coluna, não apresentam diferença significativa $(p \leq 0,05)$.

Não houve diferença entre as formulações para os valores de cinzas nos produtos crus (Tabela 2). Já nos produtos cozidos, a formulação com maior quantidade de carne (F2), apresentou maior teor de cinzas do que as formulações com fécula de mandioca e farinha de aveia (F3 e F4, respectivamente). Os hambúrgueres bovinos usados nos serviços de alimentação americanos apresentam cerca de $1,07 \%$ de cinzas após o cozimento [14]. 
De acordo com a Tabela 3, o rendimento na cocção foi maior $(p<0,05)$ para as formulações adicionadas de fécula de mandioca e farinha de aveia (F3 e F4). De forma similar, BERRY [8] encontrou maior rendimento em hambúrgueres bovinos que tinham como substitutos de gordura o alginato de sódio e o amido de mandioca, quando comparados aos produtos convencionais. No presente estudo, os valores de rendimento para as formulações F3 e F4, foram de 72,77 e 75,92\%, respectivamente, próximos ao valor de $77,1 \%$ encontrado por SWAN, ESGUERRA, FAROUK [19], em hambúrgueres feitos de carne ovina com $20 \%$ de gordura na sua formulação.

Foram observados menores valores de encolhimento na cocção $(p<0,05)$ nas formulações com fécula de mandioca e farinha de aveia (F3 e F4). BERRY [7] verificou que quanto menor o teor de gordura em hambúrgueres bovinos, maior foi o encolhimento, sendo de 18,3, 16,0 e $15,1 \%$ para os hambúrgueres com niveis de 1,3, 5,2 e $21,3 \%$ de gordura, respectivamente. No presente estudo, a porcentagem de encolhimento para as formulações $\mathrm{F} 3$ e F4 foram de 15,47 e 15,45\%, respectivamente. Isto mostra que a substituição de gordura nas formulações pela fécula de mandioca ou farinha de aveia, não aumentou o encolhimento do produto.

As formulações adicionadas de fécula de mandioca e farinha de aveia (F3 e F4) apresentaram maior capacidade de retenção de água $(\mathrm{p}<0,05)$ do que as formulações F1 e F2 (Tabela 3). Segundo PSZCZOLA [16], a fécula de mandioca possui uma alta capacidade de reter umidade, proporcionando um produto mais suculento. No entanto, a formulação adicionada de gordura (F2) não diferiu $(p>0,05)$ da formulação que utilizou apenas carne $(F 1)$, sugerindo que a adição de gordura não exerceu influência na capacidade de retenção de água do produto estudado.

Contrariamente ao reportado na literatura [7, 14], a força de cisalhamento dos hambúrgueres adicionados de gordura (F2) se apresentou maior $(\mathrm{p}<0,05)$ que a dos demais tratamentos (F1, F3 e F4) (Tabela 3). Isto pode ter sido devido, em parte, à presença de fibras de tecido conectivo na gordura ovina utilizada na formulação F2. Já os produtos adicionados de fécula de mandioca e farinha de aveia (F3 e F4), apresentaram menor força de cisalhamento $(\mathrm{p}<0,05)$ do que os sem adição de amido, indicando um efeito benéfico dos ingredientes utilizados, sobre a maciez do produto. Este efeito também foi verificado por DAWKINS et al. [9], que observaram que a adição de farelo de aveia diminui a força de cisalhamento em hambúrgueres de carne caprina.

Os hambúrgueres adicionados de gordura (F2) apresentaram menor valor de $a^{*}(p<0,05)$, ou seja, cor vermelha menos intensa, do que os das outras formulações (Tabela 4). As formulações F3 e F4 produziram hambúrgueres de maior $(\mathrm{p}<0,05)$ intensidade da cor vermelha que aquelas sem os substitutos de gordura (F1 e F2). Não houve diferença entre as formulações para os valores de b*. TROUTT et al. [21], verificaram que a adição de diferentes fontes de fibra em hambúrguer bovino, não influenciou a cor do produto, medida pelo sistema CIE
$\mathrm{L}^{*} \mathrm{a}^{*} \mathrm{~b}^{*}$. A formulação adicionada de gordura (F2) apresentou maior valor de $\mathrm{L}^{*}(\mathrm{p}<0,05)$ do que as formulações F1 e F4 (Tabela 4). Isto mostra que a adição de gordura tornou o produto mais pálido, efeito similar ao encontrado em hambúrguer bovino por TROUTT et al. [21].

TABELA 3. Valores médios ${ }^{1}(n=6)$ de rendimento e encolhimento na cocção, capacidade de retenção de água (CRA) e força de cisalhamento de hambúrgueres de carne ovina.

\begin{tabular}{ccccc}
\hline Formulação & $\begin{array}{c}\text { Rendimento na } \\
\text { cocção (\%) }\end{array}$ & $\begin{array}{c}\text { Encolhimento na } \\
\text { cocção (\%) }\end{array}$ & CRA (\%) & $\begin{array}{c}\text { Força de } \\
\text { cisalhamento } \\
\text { (kg-f) }\end{array}$ \\
\hline F1 & $65,40^{\mathrm{b}}$ & $21,42^{\mathrm{a}}$ & $59,80^{\mathrm{b}}$ & $3,64^{\mathrm{b}}$ \\
F2 & $64,43^{\mathrm{b}}$ & $20,10^{\mathrm{a}}$ & $54,64^{\mathrm{b}}$ & $4,31^{\mathrm{a}}$ \\
F3 & $72,77^{\mathrm{a}}$ & $15,47^{\mathrm{b}}$ & $73,78^{\mathrm{a}}$ & $2,02^{\mathrm{c}}$ \\
F4 & $75,92^{\mathrm{a}}$ & $15,45^{\mathrm{b}}$ & $68,63^{\mathrm{a}}$ & $2,47^{\mathrm{c}}$ \\
\hline
\end{tabular}

${ }^{1}$ Médias acompanhadas pela mesma letra, na mesma coluna, não apresentam diferenças significativas $(p \leq 0,05)$.

TABELA 4. Valores médios ${ }^{1}(n=6)$ dos parâmetros de cor $L^{*}, a^{*}$ $\mathrm{e}^{*}$ de hambúrgueres de carne ovina, medidas pelo sistema CIE.

\begin{tabular}{cccc}
\hline Formulação & $\mathrm{a}^{*}$ & $\mathrm{~b}^{*}$ & \multicolumn{1}{c}{$\mathrm{L}^{*}$} \\
\hline F1 & $8,61^{\mathrm{b}}$ & $7,44^{\mathrm{a}}$ & $37,67^{\mathrm{b}}$ \\
F2 & $7,73^{\mathrm{c}}$ & $6,99^{\mathrm{a}}$ & $42,89^{\mathrm{a}}$ \\
F3 & $9,75^{\mathrm{a}}$ & $6,74^{\mathrm{a}}$ & $39,02^{\mathrm{ab}}$ \\
F4 & $10,35^{\mathrm{a}}$ & $7,25^{\mathrm{a}}$ & $36,59^{\mathrm{b}}$ \\
\hline
\end{tabular}

${ }^{1}$ Médias acompanhadas pela mesma letra, na mesma coluna, não apresentam diferença significativa $(\mathrm{p} \leq 0,05)$.

TABELA 5. Médias ${ }^{1}$ das notas $(n=40)$ dadas pelos provadores para hambúrgueres de carne ovina com relação à aceitação global e atitude de compra.

\begin{tabular}{ccc}
\hline Formulação & Aceitação global & Atitude de compra \\
\hline F1 & $6,00^{\mathrm{a}} \pm 1,78$ & $3,33^{\mathrm{a}} \pm 1,07$ \\
F2 & $6,40^{\mathrm{a}} \pm 2,09$ & $3,53^{\mathrm{a}} \pm 1,34$ \\
F3 & $5,75^{\mathrm{a}} \pm 1,88$ & $3,05^{\mathrm{a}} \pm 1,08$ \\
F4 & $6,28^{\mathrm{a}} \pm 2,14$ & $3,45^{\mathrm{a}} \pm 1,26$ \\
\hline
\end{tabular}

${ }^{1}$ Médias acompanhadas pela mesma letra, na mesma coluna, não apresentam diferença significativa $(p \leq 0,05)$.

Não foram encontradas diferenças entre os hambúrgueres das diferentes formulações para a aceitação global do produto, nem para a atitude de compra (Tabela 5). Isto demonstra que a redução de gordura nos produtos não foi detectada pelo painel, independentemente da utilização dos substitutos. De forma diferente, BERRY [7] verificou que em hambúrgueres bovinos, à medida que o teor de gordura diminuia os atributos sensoriais como maciez e suculência também diminuiam. As médias das notas para a aceitação global variaram de 5,75 a 6,40. SWAN, ESGUERRA, FAROUK [19] utilizando escala de 9 pontos, encontraram nota média de 6,6 para 
aceitação global em hambúrgueres formulados com carne ovina temperada.

\section{4 - CONCLUSÕES}

Os hambúrgueres de carne ovina de baixo teor de gordura, adicionados de fécula de mandioca ou farinha de aveia, apresentaram melhor rendimento na cocção, melhor capacidade de retenção de água e menor força de cisalhamento do que os hambúrgueres formulados sem esses ingredientes. Quando usados em nivel de $2 \%$ da formulação pode se obter hambúrgueres baixos em gordura de qualidade aceitável representando portanto, uma alternativa viável de substituição parcial da gordura.

\section{5 - REFERÊNCIAS BIBLIOGRÁFICAS}

[1] ABULARACH, M. L., ROCHA, C. E., FELÍCIO, P. E. Características de qualidade do contrafilé (m. $L$. dorsi) de touros jovens da raça Nelore. Ciênc. Tecnol. Aliment., v. 18, n. 2, 205-210, 1998.

[2] AMERICAN DIET ASSOCIATION - ADA. Fat replacers: ADA position. J. Am. Diet. Assoc. v. 98, p. 463-468. 1998.

[3] ANDERSON, E. T., BERRY, B. W. Sensory, shear, and cooking properties of lower-fat beef patties made with inner pea fiber. J. Food Sci., v. 65. n. 5, p. 805-810, 2000.

[4] AOAC. ASSOCIATION OF OFFICIAL ANALYTICAL CHEMISTS. Official methods of Analysis of the Association of Official Analytical Chemists. 15 ed., Arlington, 1990.

[5] BECHTEL, P.J. ed. Muscle as Food. Food Science and Technology: A Series of Monographs, Academic Press, Inc., Orlando. 1986. 459p.

[6] BRASIL. MINISTÉRIO DA SAÚDE. PORTARIA n 234 de 21 de maio de 1996. Normas técnicas referentes a alimentos para fins especiais. Diário Oficial da República Federativa do Brasil, Brasília, n. 101, p. 9135 de 27 de maio de 1996. Seção1.

[7] BERRY, B. W. Low fat level effects on sensory, shear, cooking, and chemical properties of ground beef patties. J. Food. Sci. v. 57, n. 3, p. 537-540, 1992.

[8] BERRY, B. W. Sodium alginate plus modified tapioca starch improves properties of low-fat beef patties. J. Food Sci., v. 62, n. 6, p. 1245-1249, 1997.

[9] DAWKINS, N. L., PHELPS, O., McMILLIN, K. W., FORRESTER, I. T. Composition and physicochemical properties of chevon patties containing oat bran. J. Food Sci., v. 64, n. 4, p. 597-600, 1999.

[10] DESMOND, E.M., TROY, D.J., BUCKLEY, D.J. The effects of tapioca starch, oat fibre and whey protein on the physical and sensory properties of low-fat beef burgers. Food Science and Technology - Lebensmittel-Wissenschaft \& Technologie v. 31, n. 7-8, p. 653-657. 1998.
[11] EGBERT, W. R., HUFFMAN, D. L., CHEN, C., DYLEWSKI, D.P. Development of low-fat ground beef. Food Technology, v. 45, p. 64-73, 1991.

[12] GIESE, J. Developing low-fat meat products. J. Food Sci, v, 46, n. 4, p. 100-108, 1992.

[13] JAMES, N. A., BERRY, B. W. Use of chevon in the development of low-fat meat products. J. Anim. Sci. v. 75, p. 571-577, 1997.

[14] JOHNSON, L. P., WILLIAMS, S. E., NEEL, S. W., REAGAN, J. O. Foodservice industry market profile study: nutritional and objective textural profile of foodservice ground beef. J. Anim. Sci., v. 72, p. 1487-1491, 1994.

[15] MILLER, M.F., ANDERSEN, M.K., RAMSEY, C.B., REAGAN, J.O. Physical and sensory characteristics of low fat ground beef patties. J. Food Sci. v. 58, n. 3, p. 461463. 1993.

[16] PSZCZOLA, D. E. Starches and gums move beyond fat replacement. Food Technology, v. 53, n. 8, 1999.

[17] PSZCZOLA, D. E. Oat-bran-based ingredient blend replaces fat in ground beef and pork sausage. Food Technology v. 45, n. 11, 60-66. 1991.

[18] STONE, H., SIDEL, J.L. Sensory Evaluation Practices. Academic Press Inc., Orlando, 1985.

[19] SWAN, J. E., ESGUERRA, C. M., FAROUK, M. M. Some physical, chemical and sensory properties of chevon products from three New Zealand goat breeds. Small Ruminant Research, v. 28, p. 273-280, 1998.

[20] TROY, D. J., DESMOND, E. M. and BUCKEY D. J. Eating quality of low-fat beef burgers containing fat-replacing functional blends. J. Sci. Food Agric., 79, p. 507-516, 1999.

[21] TROUTT, E. S., HUNT, M. C., JOHNSON, D. E., CLAUS, J. R., KASTNER, C. L., KROPF, D. H. Characteristics of low-fat ground beef containing texture-modifying ingredients. Journal of Food Science, v. 57, n. 1, p. 1924, 1992.

[22] USDA. Composition of Foods. Beef products: raw, processed, prepared. Agric. Handbook 8-13. Human Nutritional Info. Serv., USDA., Washington, D.C, 1990.

[23] VIVIANI, E. Hamburguesas de bajo contenido graso: necesidad dietética o necesidad de mercado? La Indústria Cárnica Latinoamericana, n. 108, 1997.

[24] ZAPATA, J.F.F., NOGUEIRA, C.M., SEABRA, L.M.J., BARROS, N.N., BORGES, A.S. Composição centesimal e lipídica da carne de ovinos do Nordeste brasileiro. Ciência Rural, Santa Maria, v. 31, n. 4, p. 691-695. 2001.

\section{6 - AGRADECIMENTOS}

Ao Conselho Nacional de Desenvolvimento Científico e Tecnológico (CNPq), pelo apoio financeiro e ao Centro Nacional de Pesquisas de Agroindústria Tropical CNPAT da EMBRAPA, pelo uso dos equipamentos para as determinações de força de cisalhamento e cor. 